\title{
Ação criativa, ativismo e lutas no interior do Estado
}

\author{
Rebecca Neaera Abers
}

\section{SciELO Books / SciELO Livros / SciELO Libros}

ABERS, R. N. Ação criativa, ativismo e lutas no interior do Estado. In: ABERS, R. N., ed. Ativismo institucional: criatividade e luta na burocracia brasileira [online]. Brasília: Editora UnB, 2021, pp. 17-51. ISBN: 978-65-5846-159-3. https://doi.org/10.7476/9786558461593.0001.

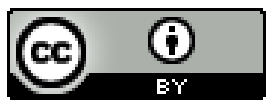

All the contents of this work, except where otherwise noted, is licensed under a $\underline{\text { Creative }}$ Commons Attribution 4.0 International license.

Todo o conteúdo deste trabalho, exceto quando houver ressalva, é publicado sob a licença Creative Commons Atribição 4.0.

Todo el contenido de esta obra, excepto donde se indique lo contrario, está bajo licencia de la licencia Creative Commons Reconocimento 4.0. 


\section{Ação criativa, ativismo e lutas no interior do Estado}

Rebecca Neaera Abers

Ativismo institucional parece uma contradição em termos. Se instituições são, por definição, ordens que se autorreproduzem, o termo ativismo evoca a ideia de transformação. Na contramão do senso comum, este livro procura sinais de agitação no interior das instituições governamentais. Encontramos grupos de servidores públicos que contestam hierarquias e o status quo, propondo maneiras alternativas de organizar as políticas governamentais ou resistindo a tentativas de desmonte de conquistas anteriores. A proposta deste livro não é afirmar que todo servidor é ou poderia ser ativista, mas, simplesmente, explorar a possiblidade de que a burocracia pode ser uma arena de luta em favor da inclusão política e da justiça social e ambiental. Quem se torna ativista? O que fazem? Quais são os recursos que usam e como? Quais estratégias empregam? Como estas estratégias mudam em diferentes contextos? São as perguntas que mobilizam esta obra.

Nesta introdução, apresento as bases teóricas para uma definição de ativismo institucional e busco, por meio da apresentação dos oito estudos empíricos incluídos neste livro, mostrar como este conceito pode ser aplicado. Estudar este fenômeno traz contribuições importantes para a pesquisa sobre 
os movimentos sociais. Nas últimas décadas, vários estudiosos desse campo colocaram a distinção rígida entre política institucional e não institucional (e entre movimentos sociais e o Estado) em xeque (BANASZAK, 2010; GOLDSTONE, 2003; GUIGNI; PASSY, 1998). Meyer (2005) e Guigni e Passy (1998) notam que, quando governos aceitam demandas de movimentos sociais, estes frequentemente ganham acesso ao processo de desenho, implementação e monitoramento da política proposta. Este livro, dando um passo além, foca em atores que defendem causas a partir de postos governamentais, sejam como servidores permanentes, sejam em cargos de confiança. Explorar este tipo de ativismo desestabiliza conceitos tradicionais na literatura de movimentos sociais sobre quem luta, quais repertórios de contestação política empregam e em quais arenas atuam.

A noção de ativismo institucional também desafia concepções prevalentes no estudo do Estado e das instituições políticas. Há mais de trinta anos, um grupo de sociólogos e cientistas políticos questionou a tendência, tanto no marxismo quanto no pluralismo, de esvaziar conceitualmente o interior do Estado, deixando-o como uma caixa preta a serviço de classes dominantes ou grupos de interesse. Ao propor "trazer o Estado de volta”, Skocpol, Rueschemeyer e Evans (1985) recuperaram a ideia weberiana de que burocratas seriam atores com seus próprios interesses, valores, inteligência e recursos. Mas a atenção cada vez maior na ciência política às instituições e, especialmente, aos mecanismos de reprodução delas, dificultou o olhar para a transformação. A mudança aconteceria, para muitos institucionalistas, apenas em “conjunturas críticas”, quando as forças de dependência da trajetória que reproduzem as instituições estivessem mais frágeis (COLLIER; COLLIER, 1991; MAHONEY, 2001). Como atores repentinamente liberados de amarras institucionais fariam suas escolhas nestas conjunturas foi pouco teorizado. Neste livro entendo burocracias como "instituições habitadas” (HALLETT; VENTRESCA, 2006). Ou seja, é impossível entender as instituições como operando por mecanismos anônimos de reprodução: é preciso examinar os valores, papéis e estratégias dos servidores públicos que participam diretamente da reprodução ou transformação delas.

O conceito de ativismo institucional evoca a ideia de contestação, mesmo se o ator nem sempre emprega o que a literatura de movimentos sociais entende como táticas contestatórias (protestos, ocupações, 
abaixo-assinados, etc). Lutar no interior das instituições pode envolver o uso de rotinas institucionais (a produção de manuais, protocolos, decretos e relatórios; a realização de reuniões e seminários técnicos, etc) para fins contestatórios. De qualquer maneira, ativismo envolve enfrentar resistências. Estudá-lo significa examinar processos que na maioria das vezes não serão bem-sucedidos, devido justamente às desigualdades de poder entre os vários atores que habitam as instituições. Movo-me não pela crença de que burocracias são normalmente transformadas por ativismo, e sim pelo exame de processos que mostram que, mesmo em uma ecologia hostil como a burocracia estatal, as sementes de luta conseguem sobreviver.

No Brasil, questionar a dicotomia entre sociedade civil e Estado como arenas distintas de ação política não é nada novo. A proliferação a partir dos anos 1990 de instituições participativas - como orçamentos participativos, conselhos gestores, conferências, etc - estimulou uma ampla literatura sobre o envolvimento de movimentos sociais em processos decisórios governamentais. A partir do governo Lula, outro fenômeno começou a capturar a atenção de estudiosos de movimentos sociais: a ocupação por ativistas de cargos governamentais (DAGNINO et al., 2006; DOWBOR, 2012; HOCHSTETLER; KECK, 2007; ABERS; SERAFIM; TATAGIBA, 2014; ABERS; OLIVEIRA, 2015; OLIVEIRA, 2016; RICH, 2013; SILVA, 2015). Inspiradas por essa literatura, as pesquisas apresentadas neste livro buscam contribuir para a construção de um marco teórico que ajude a compreender como esse tipo de ator afeta o desenho e a implementação de políticas públicas.

O objetivo desta introdução é apresentar os principais conceitos que fundamentaram o projeto de pesquisa em que os estudos contidos neste volume foram elaborados, além de sistematizar alguns dos principais achados. Nas próximas duas seções, apresento as bases teóricas do conceito de ativismo institucional. Primeiro, argumento que a definição de ativismo deve partir de um conceito de ação em geral que a entende como ao mesmo tempo criativa e situada em contextos. Realizo um levantamento seletivo de como diferentes autores explicam o papel de atores no mundo institucionalizado. Em seguida, defendo um conceito pragmatista de ação criativa que enxerga o contexto não apenas como constrangimento, mas também como constitutivo da ação. Segundo, busco na literatura sobre movimentos sociais algumas dicas sobre como definir o ativismo. Argumento que os debates 
teóricos sobre a ação coletiva e sobre confronto político são especialmente úteis para este fim. Com esses pontos de partida, na terceira seção apresento uma definição de ativismo institucional como um subtipo de ação criativa que envolve ação coletiva no interior de instituições na defesa de causas contenciosas. A quarta seção apresenta o projeto de pesquisa que orientou este livro e descreve os oito capítulos empíricos contidos nele. Essa última seção é dividida em três subseções, cada uma correspondendo a uma parte do livro. Busco mostrar como os capítulos que compõem cada parte possibilitam avanços na compreensão de três temas centrais no estudo do ativismo institucional: o processo histórico no qual são construídas as causas pelas quais os ativistas institucionais lutam; a maneira que ativistas se relacionam com os contextos institucionais, políticos e sociais em que se inserem; e a sistematização de práticas e estratégias empregadas no ativismo institucional.

\section{Ação, estrutura e criatividade}

O conceito "dupla face” de ativismo institucional se sustenta em uma concepção mais ampla de ação segundo a qual estrutura e ação são mutuamente constituídas. As instituições só existem porque são afirmadas na prática por meio da ação. Ao mesmo tempo, a ação não é apenas constrangida por instituições, mas depende delas. Na sociologia contemporânea, a mútua constituição de ação e estrutura é a pedra fundamental das obras de autores como Bourdieu (1977) e Giddens (1984). Os conceitos de habitus, de Bourdieu, e de "estruturação", de Giddens, introduzem ação na explicação das estruturas ao afirmar que a reprodução delas só acontece porque atores sociais praticam regras, normas e papéis a cada dia. Sewell (1992) repara, no entanto, que ambos os autores deram mais atenção a processos de reprodução estrutural do que à mudança. Não apresentaram explicações convincentes do porquê atores poderiam em alguns momentos resistir ou transformar as regras vigentes.

Para Sewell, duas ideias mal desenvolvidas em Giddens (1984) podem contribuir para preencher essa lacuna. Primeiro, Giddens critica a ideia de que indivíduos são cultural dopes (idiotas culturais): eles têm capacidade 
crítica; são knowledgable, ou capazes de ter conhecimento e compreensão. Segundo, Giddens teoriza que estruturas não são compostas apenas por regras que ditam o que se deve fazer em determinada situação. Estruturas também incluem recursos que atores usam quando agem.

Mesmo assim, a obra de Giddens, bem como a de Bourdieu, carecem de uma explicação teórica convincente de como atores poderiam interpretar regras e usar recursos de maneira diferente. Já que cada indivíduo é inserido cognitivamente em um mundo em que os únicos papéis e normas que conhecem são aqueles que predominam, é difícil imaginar como fariam para interromper o ciclo por meio do qual as instituições se reproduzem. ${ }^{1}$

Uma solução insatisfatória é atribuir poder transformador apenas àqueles indivíduos que detêm recursos excepcionais. O termo “empreendedor”, usado tanto na sociologia quanto na ciência política, geralmente designa indivíduos dotados de capacidades ou recursos extraordinários, o que os possibilita escapar do ciclo reprodutivo inexorável que prende as pessoas comuns. DiMaggio (1977, p. 14), em texto clássico do institucionalismo sociológico, afirma que "novas instituições surgem quando atores organizados com recursos suficientes (empreendedores institucionais) enxergam nelas uma oportunidade de realizar interesses aos quais eles atribuem alto valor”. Na ciência política, encontro ideias semelhantes. Para Dahl (1961, p. 6), por exemplo, líderes políticos são pessoas excepcionais, “que sabem usar seus recursos até o máximo”. O termo - empreendedor - também tem uso corrente na literatura de políticas públicas. Kingdon (1995, p. 122) define o empreendedor por "sua vontade de investir seus recursos - tempo, energia, reputação e às vezes dinheiro - na esperança de um retorno futuro”. Em todas essas definições, a mudança é restrita a atores com recursos extraordinários.

Pensadores mais recentes, especialmente da sociologia, criticam essa visão "heroica" da ação, que essencialmente atribui poderes transformadores apenas a atores que são tão especiais que as regras sociais não se aplicam a eles, da mesma maneira que as leis da gravidade não se aplicam

1 Deve ser notado que em palestras de Bourdieu posteriores à crítica de Sewell, a ação ganha mais vida em sua teoria do Estado. 
ao Super-Homem. Para Lawrence, Suddaby e Leca (2009, p. 1, tradução nossa), por exemplo, é necessária

uma visão mais ampla da ação em relação a instituições, uma que evite descrever atores ora como "idiotas culturais" aprisionados por arranjos institucionais, ora como empreendedores institucionais hipermusculares. ${ }^{2}$ (LAWRENCE; SUDDABY; LECA, 2009, p. 1, tradução nossa).

Encontro no pragmatismo um marco conceitual especialmente robusto para conceber a relação entre ação e estrutura de maneira que não sobrevalorize a reprodução estrutural como fazem Giddens e Bourdieu, nem remeta ao passe de mágica da ação heroica para explicar iniciativas humanas que eventualmente desafiam a reprodução. O pragmatismo encontra suas origens no pensamento de filósofos estadunidenses do século 18 e na primeira parte do século 20, como Charles Sanders Pierce, Henry James e John Dewey. Temas centrais para o pensamento pragmatista são a crítica da separação cartesiana de corpo e mente, e a ênfase no conhecimento derivado da experiência no mundo e na interação com outras pessoas. Pragmatistas também tendem a rejeitar categorias e antinomias fixas, o que facilita a compreensão de fenômenos humanos aparentemente paradoxais como o ativismo institucional. O pensamento de Dewey $(1922,1933,1934)$ é especialmente útil para esta agenda de pesquisa, pela maneira como o autor caracteriza a ação por um tensionamento constante entre rotina e mudança. O motivador central dessa tensão é a natureza "problemática” do mundo, que impossibilita a manutenção automática da rotina.

A obra mais contemporânea de Hans Joas (1996) ajuda a explicar por que o pragmatismo oferece uma solução para o problema da relação entre ação e estrutura. Joas argumenta que a sociologia da ação é dividida em duas tradições antagônicas, ambas equivocadas: a tese de que a ação é “racional”, envolvendo indivíduos inteligentes que fazem cálculos de

2 “[...] a broader vision of agency in relationship to institutions, one that avoids depicting actors either as 'cultural dopes' trapped by institutional arrangement, or as hypermuscular institutional entrepreneurs” (LAWRENCE; SUDDABY; LECA, 2009, p. 1). 
custo e benefício; e a de que o indivíduo é essencialmente um seguidor de normas ou regras definidas pela sociedade. Se a primeira tese supervaloriza a racionalidade, a segunda supervaloriza a força das estruturas sobre o indivíduo. Para Joas, no entanto, ação envolve ao mesmo tempo a inteligência do ator e sua inserção em estruturas materiais e cognitivas.

Joas bebe da ideia pragmatista de que o contexto em que o ator atua tende a ser problemático, não oferecendo regras claras que possam ser simplesmente seguidas. "Nossas ações habituais encontram resistência do mundo e reverberam de volta sobre nós” (1996, p. 128-129). Para lidar com essas reverberações, o ator experimenta. O mundo problemático exige a ação criativa, que por sua vez afeta o mundo. Por meio de processos constantes de experimentação, atores não somente aprendem sobre os problemas, mas modificam o mundo em que atuam, mesmo de forma extremamente incremental.

Chave no pensamento de Joas é a ideia de que tais atos criativos não representam a capacidade do ator de se livrar das normas culturais, papéis sociais, regras políticas ou distribuições materiais de recursos. Pelo contrário, este contexto produz a matéria-prima que o ator usa para experimentar. A experimentação prática ocorre somente porque o ator tem predisposições e valores adquiridos em seu contexto social e sua trajetória de vida. Assim, seguindo Dewey (1922), não há uma clara distinção entre o momento da rotina ou do hábito e o uso da inteligência ou vontade. A capacidade reflexiva somente pode ser usada a partir dos recursos e capacidades preexistentes.

Situações não desencadeiam nossas ações, mas também não apenas fornecem o terreno no qual realizamos nossas intenções. Nossa percepção da situação é predefinida em nossas capacidades para ação e nossa atual disposição para ação. Nossa resposta reflexiva ao desafio que nos é apresentado pela situação decide qual ação é tomada. (JOAS, 1996, p. 161, tradução nossa). ${ }^{3}$

3 "Situations do not trigger our actions, but nor do they merely provide the terrain on which we carry out our intentions. Our perception of the situation is predefined in our capacities 
Dois movimentos possibilitam a compreensão da ação como criativa nestes termos: por um lado, entender reflexividade e crítica como características humanas; por outro, abandonar a ideia de que as estruturas e instituições sociais são perfeitamente sólidas. Inspirado por pragmatistas e pelo pensamento de Joas, esse segundo movimento é chave na crítica feita por Berk e Galvan sobre o institucionalismo na ciência política:

O que aconteceria se, inspirados por pragmatistas clássicos como John Dewey e sucessores como Hans Joas, nós tratássemos a vida institucional como a experiência vivida de regras e as instituições como recursos sempre sujeitos a decomposição, rearranjados e reutilizados como resultado da própria ação? Isso significaria deixar de lado descrições de instituições como constrangimentos estruturais da ação, caminhos temporais de regularidade, mecanismos exógenos de socialização, ou padrões inculcados de cognição. [...] Ordem, bem como mudança, se tornaria resultado compreensível de ação dentro e por meio de instituições. (BERK; GALVAN, 2009, p. 543, tradução nossa). ${ }^{4}$

Se esses autores enfatizam a natureza construída das instituições, outros argumentam que sobreposições entre múltiplas instituições também impelem o ator à criatividade. Ansell (2013) sugere que, frequentemente, em vez de servirem como regras claras que nos orientam, instituições coexistem em ecologias ultracomplexas, caracterizadas por sobreposições e contradições. "Mudança institucional surge como produto das circunstâncias heterodoxas

for action and our current disposition for action. Our reflective response to the challenge presented to us by the situation decides which action is taken" (JOAS, 1996, p. 161).

4 "What if, borrowing from classical pragmatists like John Dewey and successors like Hans Joas (1993, 1996), we treated institutional life as the lived experience of rules, and institutions as always-decomposable resources, rearranged and redeployed as a result of action itself? This would mean setting aside depictions of institutions as structural constraints on action, temporal pathways of regularity, exogenous mechanisms of socialization, or ingrained patterns of cognition. [...] Order, as well as change, would become understandable outgrowths of action in and through institutions.” (BERK; GALVAN, 2009, p. 543). 
geradas por esta ecologia, que requer que atores engajam em 'criatividade situada”" (ANSELL, 2013, p. 57, tradução nossa). ${ }^{5}$

Com um foco maior em como atores enfrentam problemas morais, a "sociológica da crítica" de Boltanski e Thévenot (1999) parte da ideia de que se vive simultaneamente em múltiplos “mundos” de justificação moral. Um mesmo ato pode ser justificável no mundo doméstico, por exemplo, porém inaceitável no mundo do mercado. O conflito entre essas "ordens de grandeza” produz o que os autores chamam de controvérsias. A partir dessa proposta, os autores descrevem um processo experimental de crítica social em que atores produzem "provas" (dados, documentos, leis) que lidam com controvérsias e, eventualmente, encontram saídas.

As ideias discutidas anteriormente são apenas algumas entre uma diversidade de abordagens sociológicas e na ciência política que reafirmam o insight central de Joas de que a ação ocorre não como negação de estruturas, mas a partir delas, como enfrentamento crítico de um mundo problemático. Essa concepção ajuda a explicar a ação inserida em estruturas por duas razões. Por um lado, entendem-se as estruturas ou instituições não como ordens que automaticamente se reproduzem, mas como contextos que criam rotinas e crenças e distribuem recursos de maneira frequentemente problemática. Isso significa que não é incomum que o ator seja obrigado a usar a capacidade criativa para decidir o que fazer. Por outro lado, esses atos criativos não são superações heroicas em que o ator consegue se livrar das estruturas em que se situa. Pelo contrário, as mesmas rotinas (hábitos), crenças e recursos são a matéria-prima que o ator vai ter que usar para lidar com os problemas.

Tal concepção de ação, em que atores frequentemente são obrigados a agir criativamente com os instrumentos cognitivos e materiais disponibilizados pelo contexto problemático em que se situam, descreve ação em geral, e não somente o ativismo. As próximas seções especificam o ativismo como um subtipo de ação criativa. Para tal, trazem alguns conceitos da literatura de movimentos sociais.

5 "Institutional change arises as the product of heterodox circumstances generated by this ecology, which requires actors to engage in 'situated creativity'” (ANSELL, 2013, p. 57). 


\section{Confronto e ação coletiva}

Embora raramente dialogue explicitamente com o pragmatismo, ${ }^{6}$ boa parte da literatura sobre movimentos sociais também reconhece, pelo menos implicitamente, a qualidade dupla da ação que defendo anteriormente, ou seja, a ação é ao mesmo tempo criativa e inserida em estruturas. A própria ideia de movimento social sugere a coexistência de instituições que colocam alguns grupos sociais em condições de desvantagem estrutural e a possibilidade de que esses mesmos grupos possam promover transformações. Para explicar como atores com pouca força podem almejar à transformação, a literatura de movimentos sociais - especialmente aquela associada à chamada "teoria do processo político" - traz dois conceitos importantes: o confronto político e a ação coletiva.

A ideia de confronto surge na literatura de movimentos sociais como ponto de partida da própria discussão sobre o que distinguiria um movimento de outro tipo de agregação social. Vários autores clássicos da literatura colocaram conflitos no cerne da definição de movimento social. Touraine (1978) definiu movimentos como atores sociais envolvidos em lutas para a direção da história, o que ele chamava de historicidade. Em cada momento, o desenvolvimento histórico dependeria de conflitos específicos. Melucci (1989) definiu movimentos como uma ação coletiva que gira em torno de um conflito com "um adversário que reivindica os mesmos bens ou valores" (1989, p. 29). Esses dois autores reservavam o termo "movimento social" apenas para conflitos que eles consideravam centrais na sociedade ou, nos termos de Melucci, "sistêmicos”. Tilly (1978) não fazia essa distinção, estando mais interessado na disseminação generalizada do que chamava de "política contenciosa" (contentious politics), definida como:

6 Para exceções, ver Cefaï (2009) e Gross (2010). 
interação episódica, pública, coletiva entre reivindicadores e seus objetos quando a) pelo menos um governo é um reivindicador, objeto de reivindicação ou parte de uma reivindicação; e b) as reivindicações, se cumpridas, afetariam os interesses de pelo menos um dos reivindicadores. (MCADAM; TARROW; TILLY, 2001, p. 5, tradução nossa). ${ }^{7}$

Para Diani (1992), o foco de autores como Tilly e colegas em confronto político esconde a natureza conflituosa de muitas lutas culturais que não se manifestam em relações com governos. Para ele,

atores de movimento social se engajam em conflitos políticos e/ou culturais, com a intenção de promover a mudança social em nível sistêmico ou não sistêmico ou se opor a ela. (DIANI, 1992, p. 11, tradução nossa). ${ }^{8}$

Em resumo, todas essas discussões sugerem que movimentos envolvem disputas em torno de ordens sociais instituídas, ou seja, instituições. Alguns movimentos buscam transformar instituições existentes; outros o que Touraine (1999) chamou de movimentos históricos - lutam contra mudanças institucionais consideradas indesejáveis.

Defino as ideias que mobilizam essas lutas como causas contenciosas. Mais especificamente, proponho definir uma causa contenciosa como um objetivo que envolve a defesa ou a crítica de mudanças nas instituições que organizam as relações de poder na sociedade. Ao envolver, assim, relações institucionalizadas de poder, uma causa contenciosa precisa ser defendida contra forças poderosas de estabilidade ou mudança. Quando se trata de políticas públicas, causas contenciosas tendem a se operacionalizar

7 “[...] Episodic, public, collective interaction among makers of claims and their objects when (a) at least one government is a clamant, an object of claims, or a party to the claim; and (b) the claims would, if realized, affect the interests of at least one of the claimants.” (MCADAM; TARROW; TILLY, 2001, p. 5).

8 "Social movement actors are engaged in political and/or cultural conflicts, meant to promote or oppose social change either at the systemic or non-systemic level.” (DIANI, 1992, p. 11). 
na forma de modelos alternativos de vida ou de política pública que, se implementados, implicariam em mudanças profundas de práticas sociais estabelecidas e de relações de poder (TATAGIBA; ABERS; SILVA, 2018). Destarte, já que instituições são regras sociais que tendem a se reproduzir, pode-se dizer que causas contenciosas têm a ver, por definição, com mudança institucional, seja no sentido favorável, seja contrário.

Como distinguir uma causa contenciosa de outro tipo de ideia que mobiliza atores? Na essência da ideia de causa está a crítica ou defesa das instituições básicas que os atores entendem como causadoras das condições sociais ou políticas que detestam ou prezam. Se o fenômeno social identificado realmente tem esse poder causal a ele atribuído não é importante para esta análise: ser uma causa é uma interpretação dos atores que a defendem. Assim, uma ideia se torna uma causa contenciosa quando seus defensores acreditam que algo fundamental da sociedade ou das relações de poder está ameaçado ou em necessidade de defesa. Mesmo assim, é provável que não exista uma linha clara entre uma causa contenciosa e outros objetivos que atores podem defender, até porque sempre haverá disputas sobre as causas dos problemas sociais existentes ou sobre a relevância de diferentes assuntos.

A segunda dimensão de ação salientada pela literatura de movimentos sociais é a mobilização coletiva: movimentos envolvem a reunião de vários atores em torno de objetivos comuns. O debate sobre ação coletiva parte do reconhecimento de que Olson (1965) tinha certa razão: não é possível explicar ação coletiva coordenada entre atores em prol de um bem maior a partir dos pressupostos racionalistas e individualistas que predominam na ciência política e na economia. A capacidade de superar os dilemas de ação coletiva identificadas pela abordagem de escolha racional foi explicada de diversas maneiras, todas envolvendo situar atores em contextos mais amplos, como organizações (MCCARTHY; ZALD, 1977), redes sociais (SNOW et al., 1980; MCADAM, 1986) e dinâmicas políticas (TARROW, 1994). Outros enfatizam os contextos simbólicos: pessoas se mobilizam a partir de suas crenças sobre quais são os problemas mais importantes que a sociedade enfrenta e como resolvê-los (SNOW et al., 1986), ou ainda sobre identidades coletivas (MELUCCI, 1996), pela mobilização de emoções (JASPER, 2011), por meio de de rotinas conhecidas (TILLY, 2008), ou pela combinação entre fatores (MCADAM; MCARTHY; ZALD, 1996; 
MCADAM; TARROW; TILLY, 2001). Em resumo, essa literatura rica se dedicou intensamente a explicar por que e como atores agem coletivamente.

Vários dos autores descrevem processos de mobilização em termos muito próximos à ideia que discuto anteriormente, de que ação surge a partir de contextos, e não apesar deles. Para Melucci (1989, p. 25), por exemplo, a ação coletiva envolve um processo cognitivo por meio do qual indivíduos interpretam os contextos:

ação coletiva é [...] o produto de orientações propositais desenvolvidas em um campo de oportunidades e constrangimentos. Indivíduos agindo coletivamente constroem sua ação ao definir em termos cognitivos estas possiblidades e limites. (tradução nossa). ${ }^{9}$

Tilly (2008) também reuniu atenção para as estruturas sociais com o reconhecimento de que movimentos são criativos (GROSS, 2010). Ele usa o conceito de "repertório" para descrever o rol de rotinas e práticas conhecidas e socialmente aceitas para a ação coletiva (marchas, abaixo-assinados, barricadas, etc.) e "performance”, para descrever um ato especifico de empregar uma rotina:

a metáfora teatral chama a atenção para o caráter agrupado, apreendido, porém improvisado das interações entre pessoas quando eles fazem e recebem reivindicações. Reivindicar normalmente parece jazz e commedia dell'arte mais que a leitura ritual de escrituras. (TILLY, 2008, p. 14, tradução nossa). ${ }^{10}$

Tanto Melucci quanto Tilly exemplificam a maneira com que estudiosos de movimentos sociais exploram a mútua constituição de agência

9 "Collective action is [...] the product of purposeful orientations developed within a field of opportunities and constraints. Individuals acting collectively construct their action by defining in cognitive terms these possibilities and limits [...]” (MELUCCI, 1989, p. 25).

10 "The theatrical metaphor calls attention to the clustered, learned, yet improvisational character of people's interactions as they make and receive each other's claims. Claim making usually resembles jazz and commedia dell'arte rather than ritual reading of scripture." (TILLY, 2008, p. 14). 
e estrutura: movimentos reproduzem práticas históricas (repertórios), porque são essas que as pessoas conhecem e legitimam. Ao mesmo tempo, improvisam. Aliás, o sucesso de muitos movimentos amiúde depende da sua capacidade de surpreender (TARROW, 1994).

\section{Definindo ativismo institucional}

Com o apoio conceitual do pragmatismo e das teorias sobre movimentos sociais, construo o conceito de ativismo institucional como um tipo específico de ação criativa. Essa iniciativa acompanha uma pequena literatura fora do Brasil que vem usando o termo "ativismo institucional” (PETTINICCIO, 2012; BANASZAK, 2010), ou termos próximos como "ativismo interno" (OLSSON; HYSING, 2012). Alguns desses autores tratam de funcionários eleitos, como deputados negros ou mulheres que defendem os direitos dos grupos aos quais pertencem (SANTORO; MCGUIRE, 1997). Outros enfatizam que servidores concursados ou nomeados podem agir como ativistas. Alguns definem ativistas como trabalhadores governamentais que fazem parte de redes da sociedade civil e "agem estrategicamente de dentro da administração pública para mudar política e ação governamentais em linha com um compromisso de valor pessoal” (OLSSON; HYSING, 2012, p. 258, tradução nossa). ${ }^{11}$ Outros, como Pettinicchio (2012) e Banaszak (2010) sugerem que servidores públicos podem ser ativistas mesmo sem fazerem parte de redes de movimentos sociais externos ao Estado. Apesar de trazer contribuições importantes, nenhuma dessas definições realmente explora o que seria característica do ativismo institucional em relação a outras formas de ação no interior de instituições.

A maior parte do trabalho a ser feito aqui se relaciona à definição da primeira parte do conceito "ativismo", termo muito utilizado na literatura de movimentos sociais, porém raramente definido (JOYCE, 2014). O primeiro passo nesse sentido foi tomado na discussão sobre pragmatismo:

11 "[...] acts strategically from inside public administration to change government policy and action in line with a personal value commitment.” (OLSSON; HYSING, 2012, p. 258). 
ativismo pode ser entendido como um subtipo de ação criativa, ou seja, envolve agir reflexivamente, usando a capacidade crítica e a inteligência humana, a partir de contextos que produzem problemas, constrangimentos e recursos que possibilitam a ação. Essas características são, como Joas (1996) mostra, intrínsecas a ação intencional em geral.

A partir da discussão sobre movimentos sociais, proponho que ativismo, como subtipo de ação criativa, tem duas características especiais. Primeiro, ativismo é ação orientada para a defesa de causas contenciosas, como definidas na seção anterior. Sejam causas favoráveis ou contrárias a mudanças na organização institucional das relações de poder, essa parte do conceito incorpora o caráter conflituoso em geral associado aos movimentos sociais. Isso não quer dizer que todas as práticas ativistas sejam conflituosas: um ator pode perseguir uma causa por meio de práticas negociadoras ou conciliatórias. Mas a orientação da ação em torno de uma causa significa que mesmo práticas convencionais ou cooperativas têm como objetivo avançar a perspectiva ou agenda de um lado do confronto.

Segundo, entendo que ativismo envolve a ação coletiva. Ou seja, embora muitas vezes pessoas que têm muita iniciativa própria e comprometimento sejam consideradas ativistas, a discussão anterior chama a atenção para o ativismo como uma prática em grupo. A natureza coletiva do ativismo remete ao problema do conceito "heroico" da ação criticado anteriormente. Se ativismo evoca a imagem de pessoas com pouco poder individual lutando contra forças poderosas, a ação coletiva seria uma maneira de reunir recursos e capacidades para esse empreendimento. Em geral, ativismo é realizado por atores que, uma vez que agem coletivamente em prol de causas, participam de movimentos sociais, entendidos como um tipo de rede (DIANI, 1992). Mas a ação coletiva do ativismo também pode ocorrer por fora de movimentos sociais por meio de outros tipos de redes, como de servidores públicos ou grupos de profissionais.

Esse percurso conceitual, resumido no quadro 1, leva à seguinte definição de ativismo: ação coletiva em prol de causas contenciosas, entendidas como projetos que colocam as instituições em questão, seja para transformá-las, seja para defendê-las contra ameaças percebidas. Entendo, assim, que ativismo é por definição um tipo de ação que sempre envolve instituições. 
Quadro 1: Bases do conceito de ativismo

\begin{tabular}{|c|c|c|}
\hline \multicolumn{2}{|c|}{ Conceitos } & $\begin{array}{c}\text { Fontes de inspiração } \\
\text { teórica }\end{array}$ \\
\hline \multicolumn{2}{|c|}{ Ação e estruturas se constituem mutuamente } & \multirow{3}{*}{$\begin{array}{l}\text { Giddens, Bourdieu, } \\
\text { Sewell }\end{array}$} \\
\hline Contextos estruturais & Atores são ao mesmo & \\
\hline são "problemáticos” & "inseridos em contextos & \\
\hline \multicolumn{2}{|c|}{$\begin{array}{l}\text { Ação criativa é inteligente e situada; contexto } \\
\text { (normas e crenças sociais, distribuições de recursos } \\
\text { materiais, redes de relacionamentos) ao mesmo } \\
\text { tempo constrange e propicia instrumentos }\end{array}$} & \multirow[t]{2}{*}{ Pragmatismo } \\
\hline \multicolumn{2}{|c|}{ Ativismo é um subtipo de ação criativa } & \\
\hline $\begin{array}{l}\text { Ativismo é orientado por } \\
\text { causas contenciosas (ideias } \\
\text { que defendem ou contestam } \\
\text { instituições que organizam } \\
\text { relações de poder) }\end{array}$ & $\begin{array}{l}\text { Ativismo envolve } \\
\text { ação coletiva }\end{array}$ & $\begin{array}{l}\text { Literatura de } \\
\text { movimentos sociais }\end{array}$ \\
\hline
\end{tabular}

Da definição de ativismo para o conceito de ativismo institucional é um passo curto. A palavra institucional aqui se refere mais ao local da luta do que ao objeto: ativismo institucional seria então a ação coletiva em prol de causas contenciosas quando realizada por atores em instituições. Pode envolver ação coletiva com outros atores governamentais, com atores não governamentais, ou ambos. ${ }^{12}$

Estudar o ativismo institucional promete trazer várias contribuições para o estudo de ativismo mais geral. Toda ação - e, portanto, todo ativismo - é situada em contextos que constrangem e facilitam a ação simultaneamente. $\mathrm{O}$ ativismo no interior de instituições é de certa maneira mais

${ }^{12}$ Também entendo que ativismo pode ocorrer no interior de instituições não governamentais, como em empresas ou instituições religiosas. Embora esse tipo de ativismo não seja o objeto deste livro, deixamos a definição em aberto por hora na esperança de estimular estudos sobre esses tipos de arenas. 
constrangido do que o ativismo fora delas, já que a lógica hierárquica das organizações governamentais impõe muitas regras e limites sobre o que o ator pode fazer. Agir contra a agenda dos governantes a partir de postos governamentais pode ser especialmente difícil e exigir o que Olsson (2016) chama de subversão institucional. Ao mesmo tempo, o ativista institucional tem acesso a certos tipos de recursos que o extragovernamental não tem: publicar um protocolo a ser implementado por múltiplas instituições governamentais pode, por exemplo, ter um efeito enorme em favor de uma causa. $\mathrm{O}$ ativismo institucional pode, então, ser entendido como um caso especial de ativismo em que tanto os limites quanto os recursos para ação são especialmente grandes.

Estudar o ativismo institucional também é interessante da perspectiva do estudo das instituições estatais, por duas razões. Primeiro, ao explorar um tipo de ação que é (por definição) contestatória, esse livro torna visível um tipo de conflito que a literatura sobre processos governamentais tende a ignorar. Se estudos brasileiros sobre "presidencialismo de coalizão" apresentam o Estado brasileiro como uma arena de disputa entre múltiplos grupos políticos, o estudo do ativismo adiciona o papel de atores que podem ser marginalizados da coalizão governamental. Segundo, ao focar em ação coletiva, a presente obra contribui para debates sobre a natureza “relacional” do Estado (MARQUES, 2006), mostrando que servidores não somente operam em redes sociais, mas também em alguns casos agem juntos na construção de modelos alternativos.

\section{O projeto de pesquisa e a estrutura do livro}

Este livro resulta de um projeto de pesquisa por meio do qual propus analisar o ativismo institucional a partir da realização de estudos de caso em que atores burocráticos buscaram influenciar o desenho e a implementação de políticas públicas no Brasil. Procuro entender o ativismo institucional tanto como variável dependente (o que leva os atores a se engajarem no ativismo?), quanto como variável independente (quais são os efeitos do ativismo sobre as políticas?), mas principalmente em seu aspecto processual. Ou seja, além de entender as causas e os efeitos do ativismo, desejo 
compreender melhor como o ativismo institucional opera: quais as estratégias mais usadas? Quais recursos são mobilizados? Como essas respostas variam entre atores em diferentes tipos de posições (cargos comissionados versus servidores permanentes) ou com diferentes tipos de trajetórias e redes profissionais (pessoas com experiência de luta em movimentos sociais fora do Estado, pessoas sem este tipo de experiência)? Qual a diferença entre o ativismo institucional em torno de políticas públicas criadas com muita ou pouca participação de movimentos sociais externos ao Estado?

A escolha metodológica do estudo de caso aprofundado foi proposital, pois essa abordagem é a melhor para compreender a ação situada. Se a criatividade envolve o improviso no uso de recursos materiais, simbólicos e relacionais encontrados nas instituições em que o ator se situa, é preciso compreender a relação entre atores e instituições para entender o que fazem. Conforme classicamente definido por Yin (1984), o estudo de caso - em que um único ou vários casos são selecionados para estudo aprofundado - envolve a compreensão de um fenômeno de forma holística, em toda sua complexidade e inserido em um contexto. A realização de estudos de caso sobre uma política pública oferece a oportunidade de compreender os problemas contextualizados que os atores enfrentam. Somente assim é possível enxergar a criatividade das soluções inventadas ou os esforços contidos em atos aparentemente nada inovadores.

Contextualizar o ativismo por meio do estudo de caso aprofundado, no entanto, tem custos. É preciso não apenas entrevistar os atores identificados como potenciais "ativistas", mas traçar suas redes de interação, conhecer seus parceiros e aliados, às vezes em outras instituições. Também exige conhecer os fatores que limitam o ativismo e as forças que se opõem a ele. O pesquisador precisa assim conhecer a fundo as organizações em que os atores trabalham por meio de entrevistas não somente com os identificados como ativistas, mas com outros tipos de informantes. Ainda precisa coletar e analisar documentos oficiais e comentários públicos e levantar literaturas secundárias sobre a instituição, a política pública e o subsistema de política em tela. Em geral, um bom estudo de caso envolve dezenas de entrevistas aprofundadas com atores diversos. Esta estratégia de pesquisa naturalmente limita o número de casos que um único pesquisador poderá realizar. 
Para atingir um número de casos que permitisse certa comparabilidade, optei por orientar um conjunto de teses e dissertações; cada uma das quais contribuiria para a exploração conceitual e empírica do ativismo institucional ao mesmo tempo que constituiria uma obra em si, resultado de anos de pesquisa de cada autor. Assim, em vez de seguir um roteiro único, em que cada estudo testasse a mesma hipótese a partir da mesma base teórica, cada estudo teve uma iniciativa exploratória própria, que buscaria desenvolver insights teóricos sobre o problema do ativismo institucional a partir de diferentes experiências e em diálogo com diferentes literaturas discutidas anteriormente. Embora todos os orientandos fossem influenciados pela discussão teórica que eu desenvolvia, aquela discussão também foi evoluindo em interação com as pesquisas deles e contou com suas importantes contribuições.

Cada capítulo deste livro é baseado no marco conceitual discutido anteriormente e dialoga com outras abordagens para aprofundar teoricamente diferentes aspectos do fenômeno em tela. O livro foi dividido em três partes, cada uma delas buscando explorar uma dimensão do problema teórico do ativismo institucional.

\section{O ativismo institucional situado na história}

A primeira parte do livro examina dois casos em que redes sobrepostas de atores localizados em diferentes tipos de instituições construíram novos modelos de política pública nas décadas anteriores ao governo Lula. As redes e competências criadas durante aquele passado foram fundamentais para dar suporte ao ativismo institucional em prol dessas políticas depois de 2003.

No capítulo 1, Lucas Amaral examina o ativismo institucional na criação do Programa de Aquisição de Alimentos (PAA), política instituída no primeiro governo Lula para ser o marco central do combate à fome por meio de compras públicas da agricultura familiar. O texto reflete sobre como o conceito de enquadramentos interpretativos pode ser útil para nos ajudar a entender a complexidade e historicidade das causas contenciosas que mobilizam o ativismo institucional de burocratas, principalmente quando os ativistas não são oriundos de movimentos sociais, mas tem um perfil, em 
geral, mais acadêmico e técnico. O PAA, segundo Amaral, é uma solução para os problemas colocados à agricultura familiar e à segurança alimentar e nutricional no Brasil nas décadas anteriores. Pode ser entendido como o resultado de um trabalho de acoplamento de dois enquadramentos distintos, o do fortalecimento da segurança alimentar e nutricional e o do fortalecimento da agricultura familiar. Amaral mostra como esses enquadramentos foram sendo articulados ao longo das décadas anteriores à eleição de Lula por uma rede sobreposta de defensores localizada em diversas instituições estatais e não estatais. Dessa forma, o texto do autor contribui para este livro ao problematizar a relação entre ativismo e causas contenciosas, mostrando a utilidade do conceito de enquadramentos interpretativos no entendimento das causas que orientam o ativismo institucional.

O capítulo 2, de Igor Brandão, analisa o efeito das trajetórias profissionais de um grupo específico de atores no processo de construção institucional da Política Nacional de Resíduos Sólidos (PNRS). Para explicar como a inclusão de catadores foi adotada como componente central de um modelo alternativo de política de gestão de resíduos no Brasil, Brandão acompanha o trabalho de atores técnicos e políticos em diferentes arenas ao longo de três décadas: organizações não governamentais, governos locais, fóruns temáticos, organismos internacionais, o governo federal, entre outros. Em diálogo com literaturas sobre circulação de elites, redes de governança, e mudança institucional, o autor argumenta que as trajetórias constituídas a partir da experiência em arenas do Estado e da sociedade civil produziram um "efeito ricochete", gerando competências e reconhecimentos tais que habilitaram esse grupo de atores a mediar a mudança do regime brasileiro de políticas de resíduos.

Ambos os estudos situam o ativismo institucional do período petista na história de lutas institucionais e não institucionais de grupos de atores que vinham construindo não somente ideias, mas também redes e capacidades no período anterior. Esses recursos contribuiriam decisivamente para criar apoio político para tais agendas. Os estudos atentam para o fato de que causas são construções históricas e de que a capacidade de ativistas influenciarem as políticas públicas é frequentemente criada a longo prazo. Os grupos de burocratas ativistas que defenderam esses modelos (bem como outros discutidos em outras partes do volume) foram formados ao 
longo de décadas de experimentação, em governos locais, em entidades não governamentais, por meio de projetos de pesquisa e extensão universitários, e em outras arenas.

Os capítulos mostram que o processo de experimentação opera em múltiplos níveis. Por um lado, é por meio de várias experiências anteriores que os atores constroem os conceitos básicos de um modelo alternativo. Por outro lado, esses processos experimentais também promovem a criação de capacidades técnicas e de redes de apoio que podem ser mobilizadas futuramente. Assim, em consonância com a perspectiva pragmatista, esses estudos demonstram que a experimentação não somente produz aprendizado no sentido de aperfeiçoar conhecimentos, mas também transforma o terreno de ação em que ocorre a ação criativa.

\section{O ativismo institucional situado em contextos}

Se a primeira parte do livro situa o ativismo institucional em histórias de luta, a segunda parte mostra o valor de enxergar o ativismo como situado em contextos que fornecem matéria-prima para a ação.

No capítulo 3, Marilia Oliveira analisa a atuação de um conjunto de burocratas oriundos do movimento ambientalista que assumiram cargos no Ministério de Meio Ambiente sob o comando de Marina Silva. O capítulo busca explicar como esses atores conseguiram promover uma política pública de substancial impacto, o Plano de Prevenção e Combate ao Desmatamento na Amazônia (PPCDAm). Seguindo a proposta de Tatagiba, Abers e Silva (2018), Oliveira analisa esse processo como fruto da interação entre vários níveis de análise: o regime (a coalizão política que incorporou Silva ao governo Lula), o subsistema de política pública (política ambiental) e o movimento social (ambientalista). O argumento central é que os ambientalistas conseguiram reunir capacidade técnica com capacidade político-partidária. A primeira se acumulava a partir do trabalho anterior em Organizações Não Governamentais ambientalistas altamente profissionalizadas, de maneira semelhante ao que foi visto nos casos do PAA e da gestão de resíduos sólidos. A segunda vinha da relação entre segmentos do movimento ambientalista com o Partido dos Trabalhadores 
e com o governo Lula. A participação de membros do movimento em posições chaves da coalizão política é fator importante para explicar a implementação do programa.

No capítulo 4, Luiz Vilaça estuda um grupo de procuradores do Ministério Público Federal envolvidos na construção da barragem hidrelétrica de Belo Monte. Ele procura explicar por que um grupo deles se tornou defensor ferrenho das comunidades atingidas pela obra. Vilaça testa e descarta as duas teses dominantes na literatura para explicar os compromissos de burocratas, a autosseleção de pessoas com determinados valores no momento da entrada no serviço público e a socialização por uma cultura organizacional após a contratação. O autor argumenta que o comprometimento de alguns procuradores com a causa das comunidades afetadas é resultado de um terceiro fator, o contato com as populações afetadas após chegar à cidade. Assim, ao mostrar que o compromisso com causas derivou da interação com atores da sociedade no cotidiano do trabalho dos procuradores, o capítulo contribui para este debate sobre como a inserção do ator em um contexto afeta suas identidades e preferências.

O capítulo 5, de Ana Karine Pereira, examina o mesmo caso, a partir de outra ótica. Para entender como atores estatais mobilizam recursos existentes nas instituições em que trabalham, a autora explora como analistas ambientais responsáveis por emitir pareceres sobre a concessão de licenciamento ambiental da hidrelétrica de Belo Monte tentaram diminuir os impactos sobre comunidades locais. Para tal, buscaram recursos em duas dimensões do contexto institucional, a autonomia (entendida como a capacidade de agir) e a discricionariedade (entendida como liberdade de agir). A autora mostra que a discricionariedade em torno do processo de licenciamento ambiental, resultado da ambiguidade das regras sobre os procedimentos técnicos a serem realizados, permitiu que os técnicos interpretassem seu papel no processo de aprovação da licença de maneira criativa. A falta de autonomia, no entanto, limitou o alcance dessas ações. Desse modo, a análise da discricionariedade e da autonomia serve como uma janela útil para entender a dupla face das estruturas institucionais, que operam ao mesmo tempo como constrangimentos e como recursos que possibilitam a ação. 
No capítulo 6, Mariana Cartaxo aponta para a percepção dos ativistas institucionais sobre sua capacidade de agir ao examinar como servidores da política de AIDS interpretam mudanças no contexto organizacional de seu trabalho. Desde os anos 1990, a política nacional de AIDS tem sido caracterizada pela construção conjunta de uma rica rede de atores estatais e não estatais (RICH, 2013). O estudo de Cartaxo examina o impacto, em 2009, da criação do Departamento de IST, AIDS e Hepatites Virais (Diahv) do Ministério da Saúde. A partir da obra de Hallett e Ventresca (2006), a autora explora como atores que "habitam" instituições as interpretam simbolicamente. Ela mostra como a criação do departamento abalou a crença entre servidores de que tinham autonomia para criar as "redes de sociabilidade" que viabilizavam a política. Assim, esse estudo ajuda a entender a maneira como servidores ativistas comprometidos com um modelo alternativo de gestão agem a partir de suas crenças sobre mudanças institucionais.

Examinar lutas que ocorrem no interior de instituições coloca em xeque pressupostos de boa parte da literatura sobre movimentos sociais que compreende as instituições políticas como "estruturas de oportunidades" externas aos movimentos. Em texto recente, com Silva e Tatagiba (TATAGIBA; ABERS; SILVA, 2018), proponho redefinir oportunidades políticas como estruturas relacionais em que atores são inseridos. A intenção é mostrar que contextos não devem ser entendidos como condições externas que limitam a ação, e sim como um conjunto de relações em que o ator participa.

Ao mostrar que ativistas fazem parte das relações sociais que compõem o contexto, os textos dessa parte do livro dão sustento a essa proposta. No caso do combate ao desmatamento (capítulo 3), os atores do movimento ambientalista faziam parte, mesmo de maneira marginalizada, do regime político vigente, especialmente em função da liderança de Marina Silva, ator ao mesmo tempo partidário e ambientalista. Nos casos de Belo Monte (capítulos 4 e 5), o ativismo dos técnicos de licenciamento ambiental e dos procuradores é dificultado não tanto por instituições anônimas quanto pela força de outros atores (criativos) no governo que defendiam o avanço acelerado da obra.

Os textos também mostram a maneira complexa por meio da qual os contextos criam condições para a ação. No texto de Pereira (capítulo 5), regras ambíguas criam possiblidades para ação discricionária e instituições 
que distribuem poder para outros atores diminuem a influência dos ativistas, mas nenhum desses fatores instrucionais determina o que os atores vão fazer. Foi por meio de interações com outros atores estatais e não estatais que os técnicos de licenciamento ambiental construíram suas estratégias criativas. O texto de Cartaxo sobre a política de AIDS (capítulo 6) também acentua a natureza indeterminada do arranjo institucional em que atores se situam ao chamar a atenção para como grupos de atores constroem simbolicamente interpretações sobre as estruturas institucionais e sobre o efeito delas em sua capacidade de agir.

\section{O ativismo institucional em ação}

Na última parte do livro, os capítulos oferecem importantes análises não somente para entender os antecedentes e condicionantes do ativismo, mas também para explorar como o ativismo acontece, ou seja, para identificar práticas e estratégias típicas do ativista que age no interior de instituições.

No capítulo 7, Rafael Viana explora uma política desenhada em proximidade com movimentos populares, o Programa Minha Casa Minha Vida - Entidades (MCMV-E). Desde o início do governo Lula, o movimento de moradia discutiu com o Ministério das Cidades a implementação de um modelo alternativo de produção de habitação popular baseado na autogestão por entidades de moradores. Essas experiências foram atropeladas pela criação do Programa Minha Casa Minha Vida em 2009, que se organizava em torno de um modelo completamente diferente, de construção por empreiteiras. Em resposta a críticas dos movimentos, o MCMV-E foi criado baseado no modelo autogestionário. Viana examina o papel de burocratas do programa - a maioria dos quais não era originária dos movimentos - na defesa deste modelo. Em diálogo com o pragmatismo francês, Viana contribui para o estudo de “como” opera o ativismo, mostrando o papel de ativistas institucionais como mediadores e tradutores entre Estado e movimentos sociais em torno da controvérsia entre diferentes modelos de produção de habitação popular.

No capítulo 8, Ana Marusia Pinheiro Lima lança o olhar para longe da burocracia federal, examinando o papel de servidores em legislaturas 
locais na condução de "Parlamentos Mirins”, programas implementados por câmaras de vereadores em que crianças e adolescentes interpretam o papel de políticos. No único capítulo do livro baseado em um estudo de múltiplos casos (foram selecionados cinco programas após um levantamento mais amplo do universo), a autora analisa como essa agenda, aparentemente pouco contestatória, acaba avançando apenas em função da luta de servidores municipais que a interpretam como uma causa contenciosa. O foco deste capítulo são as estratégias que ativistas empregam para garantir a sobrevivência dos Parlamentos Mirins. A autora mostra que os defensores desses programas precisavam mobilizar recursos e redes de apoio tanto dentro do parlamento quanto em entidades externas, e manejar complexas relações hierárquicas entre burocratas e parlamentares.

O capítulo 9, de Paula Pompeu Fiuza Lima, apresenta o único caso incluído no livro em que os atores não identificavam sua agenda como uma causa contenciosa: a averiguação cadastral do Programa Bolsa Família (PBF). A inclusão desse estudo se provou útil para investigar a diferença entre ativismo e outras formas de ação criativa na burocracia. Enquanto alguns órgãos do governo federal passaram por um influxo de ativistas de movimentos sociais no início do governo Lula, o PBF se destacou pela alta qualificação técnica e pela ausência de participação social. Havia, no entanto, uma controvérsia importante no interior do PBF em torno da qual os atores se mobilizavam: qual erro cadastral deveria ser alvo central da averiguação, a inclusão indevida ou a exclusão indevida? Se, no primeiro momento, a pressão política para aumentar o número de beneficiários valorizava a preocupação com exclusões indevidas, em contextos de contenção de recursos e de fortalecimento das forças conservadoras, as acusações de fraude na inclusão se tornaram mais salientes. O foco do capítulo é em como, nesses contextos cambiantes, os atores experimentavam com diferentes soluções técnicas para garantir a legitimidade da averiguação cadastral.

A comparação entre esses últimos casos facilita pensar um pouco a diferença entre o ativismo institucional e outras formas de ação criativa. A ampla literatura sobre burocracia, especialmente a de nível de rua, já demonstra que empregados públicos exercem discricionariedade e agem a partir de valores (LIPSKY, 2010; MAYNARD-MOODY; MUSHENO, 2003; DUBOIS, 2010). A literatura sobre burocracia de médio escalão cita 
diversas práticas realizadas por esse tipo de trabalhador, como intermediar superiores, pares e subordinados; organizar e disseminar informações; negociar, lidar com conflitos, alocar recursos, entre outras (LOTTA; PIRES; OLIVEIRA, 2014, p. 472). Nos estudos apresentados aqui, todos envolvendo burocratas de médio escalão, também se encontram relatos de práticas semelhantes, independentemente da existência do que se demarcou como ativismo. Tanto os defensores do empoderamento das entidades de moradia (capítulo 7), quanto os técnicos do cadastro da Bolsa Família (capítulo 9) buscaram lidar com a diminuição de apoio político para suas agendas por meio de processos de experimentação criativa no desenho do programa. Isso sugere que nem sempre ativistas utilizam estratégias diferentes do que as empregadas por não ativistas, algo já detectado por Banaszak (2010).

Como o ativismo institucional se diferencia, então, de outras formas de ação criativa nas instituições? Novamente, a comparação do caso do Bolsa Família com outros exemplos pode ser de grande ajuda. Políticas públicas normalmente envolvem controvérsias (ZITTOUN, 2014). Uma causa pode ser entendida como um tipo específico de controvérsia, aquele que gira em torno de diferentes valores sobre estruturas institucionais de poder. Assim, pode-se dizer que, embora houvesse controvérsias em todos os casos, nem sempre elas poderiam ser tipificadas como causas. A controvérsia identificada por Paula Pompeu no capítulo 9 (entre priorizar evitar erros de inclusão versus erros de exclusão no momento da averiguação cadastral) não se trata de uma causa. Trata-se de uma controvérsia de ordem moral significativa, mas sua solução não passa por uma transformação fundamental na organização do poder. Curiosamente, os dois lados da controvérsia construíram justificativas em torno do que Boltanski e Thévenot (1999) entenderiam como uma mesma ordem de grandeza. Aqueles que defendiam a inclusão à base de autodeclaração valorizavam a criação de uma meta operacional que possibilitasse a maior cobertura do programa em menor tempo; já quem se preocupava em evitar inclusões indevidas justificava essa posição em termos de limitações de recursos: cada indivíduo incluído indevidamente estaria ocupando a vaga de outro que precisaria mais. A divergência não tinha a ver com diferentes entendimentos sobre as estruturas institucionais de poder, e sim sobre qual seria a lógica de custo e benefício mais adequada para garantir o mesmo resultado. 
De maneira diferente, o MCMV-E (capítulo 7) propôs reorganizar relações de poder na gestão pública ao empoderar entidades populares na implementação, algo que tem em comum com o PAA (capítulo 1) e com a agenda inclusiva de resíduos sólidos (capítulo 2). A implementação desses modelos alternativos implicaria então não somente em diferentes desenhos de políticas, mas também em mudanças de alocação de autoridade sobre a política. Essas propostas claramente podem ser entendidas como causas. Comparando os casos anteriormente citados ao do Bolsa Família, talvez não surpreenda que o trabalho "experimental” descrito por Pompeu pareça ser um processo de adaptação relativamente tranquilo em comparação com as lutas para transformar percepções sobre a natureza do bem público em que funcionários do MCMV-E se engajavam. Os defensores da causa autogestionária questionavam as próprias bases dos argumentos custo-benefício que prevalecem no serviço público e que foram usados para justificar modelos empresariais de produção de moradia. Para eles, o empoderamento de entidades populares seria mais importante do que a lógica da eficiência. Ou seja, a causa da autogestão envolveu lutas sobre a distribuição de poder e não apenas sobre o desenho adequado da política pública.

Na defesa de políticas mais contenciosas discutidas nesta seção (MCMV-E e os Parlamentos Mirins), os autores identificam duas estratégias distintas. Primeiro, os atores embarcaram na construção de redes mais amplas. Os atores que se organizaram para adaptar a averiguação do PBF se restringiam principalmente a um círculo fechado de técnicos. Nos casos do MCMV-E e dos Parlamentos Mirins, ganhar apoio para as políticas exigiu a construção de redes com atores em instituições mais diversas, como órgãos federais e subnacionais, no caso do MCMV-E, e entidades da sociedade civil no caso dos Parlamentos. Segundo, nesses dois estudos, os autores descrevem táticas em que os ativistas buscaram desarmar a própria natureza contenciosa do modelo de política proposto. Para o MCMV-E, isso envolveu a disseminação de novas ideias no interior da burocracia. No caso dos Parlamentos Mirins, demandou a busca por diversos patrocínios políticos para o programa, de maneira a desassociá-lo de um interesse político específico. 


\section{8. À procura do possível}

Nesta introdução, busquei apresentar um marco conceitual que foi desenvolvido com um grupo de estudantes do Programa de Pós-Graduação em Ciência Política da Universidade de Brasília ao longo de vários anos de debates. Se cada capítulo é de algum modo inspirado em uma proposta do conceito de ativismo institucional apresentado pela orientadora alguns anos atrás, cada autora e autor também ajudou a refinar e aprofundar esse conceito em um processo rico de construção coletiva. Esta introdução tentou repassar para o leitor o caminho percorrido, passando por teorias institucionalistas, a sociologia da ação, o pragmatismo, teorias de movimentos sociais, de políticas públicas e da burocracia. Esta busca por sintetizar teorias institucionalistas e de movimentos sociais não é só minha: outros autores vêm percebendo o potencial de melhor entender a relação entre ação e estrutura por meio do encontro entre várias perspectivas (MCADAM; SCOTT, 2005; SCHNEIBERG; LOUNSBURY, 2008; FLIGSTEIN; MCADAM, 2012). Essa bricolagem conceitual pode parecer um pouco dispersa, mas foi necessária para enfrentar o desafio de analisar um tipo de ação que não respeitava as fronteiras conceituais existentes.

Além de interpretar o passado, acredito que a perspectiva proposta aqui nos ajudará a pensar sobre o que pode acontecer na próxima fase histórica, já em curso no momento de publicação desta obra. A ideia central que tentei passar nesta introdução é que ativismo envolve buscar em contextos institucionais os recursos e relacionamentos que podem ser usados para avançar uma causa contenciosa. Se o contexto institucional é, na verdade, uma configuração relacional de atores, a mudança de contexto é uma mudança naquela configuração. Ao longo dos últimos anos, surgiram no Brasil novas organizações políticas à direita que mobilizam parte da população e que ganham cada vez mais acesso às instituições governamentais. Com a vitória da extrema direita nas urnas, o contexto mudou profundamente.

A mobilização de atores ideologicamente à direita deve também ser compreendida como ativismo. Causas contenciosas podem ser conservadoras, envolvendo não somente a defesa de mudança, mas a crítica a mudanças em curso ou propostas que podem reorganizar as relações de poder na sociedade. Como os estudos incluídos neste volume demostram, a luta pela 
ampliação de direitos e igualdade política e social já enfrentava oposição nas gestões anteriores. Embora os governos petistas tenham criado algumas oportunidades, a presença crescente de defensores de outros interesses e ideias na coalizão governamental significou que sempre foi necessário lutar para manter e avançar as políticas de inclusão e empoderamento de grupos marginalizados. A partir de 2019, as possibilidades de agir em prol dos direitos sociais e ambientais de dentro das estruturas burocráticas se tornou muito mais difícil.

Assim, este livro sai do prelo em um contexto completamente diferente daquele em que a pesquisa foi realizada, com boa parte das políticas públicas estudadas se encontrando hoje em processo de franco desmonte. Neste contexto, há duas questões centrais para acompanhar. Primeiro, em que medida ativismo institucional à direita se diferencia do ativismo em defesa da inclusão política e social? Segundo, como servidores públicos comprometidos com políticas de inclusão e direitos lidarão com o fortalecimento dos adversários no interior da burocracia federal? Sem dúvida, vive-se hoje em um período de retrocesso dessas agendas. No entanto, o estudo do ativismo é por natureza menos um rastreamento do provável do que uma procura do possível. Os radares continuarão ligados em busca do improviso inesperado.

\section{Referências}

ABERS, Rebecca Neaera; OLIVEIRA, Marília Silva. Nomeações políticas no Ministério do Meio Ambiente (2003-2013): interconexões entre ONGs, partidos e governos. Opinião Pública, v. 21, n. 2, p. 336-364, 2015.

ABERS, Rebecca Neaera; SERAFIM, Lizandra; TATAGIBA, Luciana. Repertórios de interação estado-sociedade em um Estado heterogêneo: a experiência na era Lula. Dados - Revista de Ciências Sociais, v. 57, n. 2, p. 325-357, 2014.

ABERS, Rebecca Neaera; SILVA, Marcelo Kunrath; TATAGIBA, Luciana. Movimentos sociais e políticas públicas: repensando atores e oportunidades políticas. Lua Nova: Revista de Cultura e Política, n. 105, p. 15-46, 2018. 
ANSELL, Chris. Ecological Explanation. In: BERK, Gerald; GALVAN, Dennis C.; HATTAM, Victoria (org.). Political Creativity: Reconfiguring Institutional Order and Change. Philadelphia: University of Pennsylvania Press, 2013. p. 55-77.

BANASZAK, Lee Ann. The women's movement inside and outside the State. [S.l.]: Cambridge University Press, 2010.

BERK, Gerald; GALVAN, Dennis. How people experience and change institutions: a field guide to creative syncretism. Theory and society, v. 38, n. 6, p. 543-580, 2009.

BOLTANSKI, Luc; THÉVENOT, Laurent. The Sociology of Critical Capacity. European Journal of Social Theory, v. 2, n. 3, p. 359-377, 1999.

BOURDIEU, Pierre. Outline of a theory of practice. Translated by Richard Nice. [S.l.]: Cambridge University Press, 1977.

CEFAÏ, Daniel. Como nos mobilizamos? A contribuição de uma abordagem pragmatista para a sociologia da ação coletiva. Dilemas: Revista de estudos de conflito e controle social, v. 2, n. 4, p. 11-48, 2009.

COLLIER, Ruth Berins; COLLIER, David. Shaping the political arena: critical junctures, the labor movement, and regime dynamics in Latin America. Princeton, NJ: Princeton University Press, 1991.

DAGNINO, Evelina; OLVERA, Alberto J.; PANFICHI, Aldo. Para uma outra leitura da disputa pela construção democrática na América Latina. In: DAGNINO, Evelina; OLVERA, Alberto J.; PANFICHI, Aldo (org.). A disputa pela construção democrática na América Latina. São Paulo: Paz e Terra, 2006. p. 13-92.

DAHL, Robert Alan. Who governs? Democracy and power in an American city. New Haven: Yale University Press, 1961.

DEWEY, John. Human Nature and Conduct. New York: The Modern Library, 1922.

DEWEY, John. How We Think. [S.l.]: Forgotten Books, 1933. 
DEWEY, John. Art as Experience. New York: Minton, Balch \&amp; Company, 1934.

DIANI, Mario. The concept of social movement. The sociological review, v. 40, n. 1, p. 1-25, 1992.

DIMAGGIO, Paul. Interest and agency in institutional theory. In: ZUCKER, Lynne G. (org.). Institutional patterns and organizations: culture and environment. Cambridge, MA: Ballinger Publishing Company, 1977. p. 3-32. DOWBOR, Monika. Arte da institucionalização: estratégias de mobilização dos sanitaristas (1974-2006). 2012. 288 f., il. Tese (Doutorado em Ciência Política) - Faculdade de Filosofia, Letras e Ciências Humanas, Universidade de São Paulo, São Paulo, 2012.

DUBOIS, Vincent. The bureaucrat and the poor: encounters in French welfare offices. London: Ashgate, 2010.

FLIGSTEIN, Neil; MCADAM, Doug. A theory of fields. New York: Oxford University Press, 2012.

GIDDENS, Anthony. The constitution of society: outline of the theory of structuration. [S.l.]: University of California Press, 1984.

GOLDSTONE, Jack A. Bridging institutionalized and noninstitutionalized politics. In: GOLDSTONE, Jack A. (org.). States, parties, and social movements. Cambridge, NY: Cambridge University Press, 2003. p. 1-24. GROSS, Neil. Charles tilly and American pragmatism. The American Sociologist, v. 41, n. 4, p. 337-357, 2010.

GUIGNI, Marco; PASSY, Florence. Contentious politics in complex societies: new social movements between conflict and cooperation. In: GIUGNI, Marco; MCADAM, Doug; TILLY, Charles (org.). From contention to democracy. Boulder: Rowman \& Littlefield, 1998. p. 81-108.

HALLETT, Tim; VENTRESCA, Marc J. Inhabited institutions: social interactions and organizational forms in Gouldner's Patterns of Industrial Bureaucracy. Theory and society, v. 35, p. 213-236, 2006. 
HOCHSTETLER, Kathryn; KECK, Margaret E. Greening Brazil: environmental activism in State and society. Durham and London: Duke University Press, 2007.

JASPER, James M. Emotions and social movements: twenty years of theory and research. Annual Review of Sociology, v. 37, n. 1, p. 285-303, 2011. JOAS, Hans. The creativity of action. Chicago: University of Chicago Press, 1996.

JOYCE, Mary C. Activism success: a concept explication. 2014. 107 f., il. Thesis (Master's degree) - Department of Communication, University of Washington, Washington, DC, 2014.

KINGDON, John W. Agendas, alternatives, and public policies. [S.l.]: Harper Collins College Publishers, 1995.

LAWRENCE, Thomas B.; SUDDABY, Roy; LECA, Bernard. Institutional work: actors and agency in institutional studies of organizations. Cambridge: Cambridge University Press, 2009.

LIPSKY, Michael. Street-Level Bureaucracy, 30th Anniversary Edition: Dilemmas of the Individual in Public Service. New York: Russell Sage Foundation, 2010.

LOTTA, Gabriela Spanghero; PIRES, Roberto Rocha C.; OLIVEIRA, Vanessa Elias. Burocratas de médio escalão: novos olhares sobre velhos atores da produção de políticas públicas. Revista do Serviço Público, v. 65, n. 4, p. 463-492, 2014.

MAHONEY, James. The legacies of liberalism: path dependence and political regimes in Central America. Baltimore: John Hopkins University Press, 2001.

MARQUES, Eduardo Cesar. Redes sociais e poder no Estado brasileiro: aprendizados a partir das políticas urbanas. Revista Brasileira de Ciências Sociais, v. 21, n. 60, p. 15-41, 2006. 
MAYNARD-MOODY, Steven Williams; MUSHENO, Michael Craig. Cops, teachers, counselors: stories from the front lines of public service. Ann Arbor: University of Michigan Press, 2003.

MCADAM, Doug. Recruitment to high-risk activism: the case of Freedom Summer. American journal of sociology, v. 92, n. 1, p. 64-90, 1986.

MCADAM, Doug; MCCARTHY, John D.; ZALD, Mayer N. Introduction: Opportunities, mobilizing structures, and framing processes - toward a synthetic, comparative perspective on social movements. In: MCADAM, Doug; MCCARTHY, John D.; ZALD, Mayer N. (org.). Comparative perspectives on social movements: political opportunities, mobilizing structures, and cultural framings. New York: Cambridge University Press, 1996. p. 1-22.

MCADAM, Doug; SCOTT, W. Richard. Organizations and Movements. In: DAVIS, Gerald F. et al. (org.). Social movements and organization theory. New York: Cambridge University Press, 2005. p. 4-40.

MCADAM, Doug; TARROW, Sidney G.; TILLY, Charles. Dynamics of contention. Cambridge: Cambridge University Press, 2001.

MCCARTHY, John D.; ZALD, Mayer N. Resource mobilization and social movements: a partial theory. American journal of sociology, v. 82, n. 6 , p. 1212-1241, 1977.

MELUCCI, Alberto. Nomads of the present. Philadelphia: Temple University Press, 1989.

MELUCCI, Alberto. Challenging codes: collective action in the information age. [S.l.]: Cambridge University Press, 1996.

MEYER, David S. Social movements and public policy: eggs, chicken, and theory. In: MEYER, David S.; JENNESS, Valerie; INGRAM, Helen M. (org.). Routing the opposition: social movements, public policy, and democracy. Minneapolis: University of Minnesota Press, 2005. p. 1-26. 
OLIVEIRA, Marília Silva de. Movimento para as instituições: movimento ambiental, partidos políticos e a liderança de Marina Silva. 2016. 303 f., il. Tese (Doutorado em Ciência Política) - Instituto de Ciência Política, Universidade de Brasília, Brasília, 2016. OLSON, Mancur. The logic of collective action: public goods and the theory of groups. Cambridge, MA: Harvard University Press, 1965.

OLSSON, Jan. Subversion in institutional change and stability: a neglected mechanism. London: Palgrave Macmillan, 2016.

OLSSON, Jan; HYSING, Erik. Theorizing inside activism: understanding policymaking and policy change from below. Planning theory \& practice, v. 13, n. 2, p. 257-273, 2012.

PETTINICCHIO, David. Institutional activism: Reconsidering the insider/ outsider dichotomy. Sociology compass, v. 6, n. 6, p. 499-510, 2012.

RICH, Jessica A. J. Grassroots bureaucracy: intergovernmental relations and popular mobilization in Brazil's AIDS policy sector. Latin American politics and society, v. 55, n. 2, p. 1-25, 2013.

SANTORO, Wayne A.; MCGUIRE, Gail M. Social movement insiders: the impact of institutional activists on Affirmative Action and comparable worth policies. Social problems, v. 44, p. 503-519, 1997.

SCHNEIBERG, Marc; LOUNSBURY, Michael. Social movements and institutional analysis. In: GREENWOOD, Royston et al. (org.). The sage handbook of organizational institutionalism. Thousand Oaks, CA: Sage, 2008. p. 648-670.

SKOCPOL, Theda; RUESCHEMEYER, Dietrich; EVANS, Peter B. (org.). Bringing the State back in. [S.l.]: Cambridge University Press, 1985.

SEWELL JR, William H. A theory of structure: duality, agency, and transformation. American journal of sociology, v. 98, p. 1-29, 1992. 
SILVA, Marcelo Kunrath. Espaços e Repertórios: a atuação dos movimentos sociais através das fronteiras da sociedade civil e do Estado. In: SCHERER-WARREN, Ilse; LÜCHMANN, Lígia Helena H. (org.). Movimentos sociais e engajamento político: trajetórias e tendências analíticas. Florianópolis: Editora UFSC, 2015. p. 133-160.

SNOW, David A. et al. Frame alignment processes, micromobilization, and movement participation. American sociological review, v. 51, n. 4, p. 464-481, 1986.

SNOW, David A.; ZURCHER JR, Louis A.; EKLAND-OLSON, Sheldon. Social networks and social movements: a microstructural approach to differential recruitment. American sociological review, p. 787-801, 1980.

TARROW, Sidney G. Power in movement: social movements, collective action and politics. Cambridge: Cambridge University Press, 1994.

TATAGIBA, Luciana; ABERS, Rebecca; SILVA, Marcelo Kunrath. Movimentos sociais e políticas públicas: ideias e experiências na construção de modelos alternativos. In: PIRES, Roberto Rocha C.; LOTTA, Gabriela Spanghero; OLIVEIRA, Vanessa Elias (org.). Burocracia e políticas públicas no Brasil: intersecções analíticas. Brasília: Enap/Ipea, 2018. p. 105-138. TILLY, Charles. From mobilization to revolution. Reading, MA: Addison-Wesley Pub. Co., 1978.

TILLY, Charles. Contentious performances. [S.l.]: Cambridge University Press, 2008.

TOURAINE, Alain. La voix et le regard. Paris: Les Édition du Seuil, 1978. YIN, Robert K. Case study research: design and methods. London: SAGE, 1984. ZITTOUN, Philippe. The political process of policymaking: a pragmatic approach to public policy. [S.l.]: Springer, 2014. 